\title{
Penerapan Server Web Hosting Berbasis Linux Ubuntu pada Jaringan Komputer SD Negeri 15 Pangkalpinang
}

\author{
Mohammad Akis \\ Program Studi Teknik Informatika \\ STMIK Atma Luhur \\ J1. Jend. Sudirman, Selindung, Pangkalpinang \\ mohammadakis@gmail.com
}

\author{
Eka Pebriyanto \\ Program Studi Teknik Informatika \\ STMIK Atma Luhur \\ J1. Jend. Sudirman, Selindung, Pangkalpinang \\ ekapebriyanto@atmaluhur.ac.id
}

\begin{abstract}
The purpose of this research is to implement Server Web Hosting based Linux Ubuntu in Computer System/network of Elementary School 15 (SDN 15) Pangkalpinang, because there is not available of Computer Server Web Hosting as storage media of website based application and school website at Elementary School 15 Pangkalpinang, makes the school wants to create a unit of Server Web Hosting. The research methods of this thesis is analitic method and design method where at analitic method, writer analyzes the needs and with the analysis writer designs the steps to be done. Then, kind of this research is applied research, it means to give solution of a certain problem practically and to support development activities or implementation of a system , such as database, programming language, network concept. In order that project implementation is on time, so project model is used. The result of this is Server Web Hosting which can give services like DNS Server, FTP Server, File Server, Mail Server that can be accessed by clients through certain links. The conclusion, after server is implementatied can facilitate every one to access any informations from Elementary School 15 fast and easily anytime.
\end{abstract} Hosting

Keywords-Server, Hosting, Web Server, Wabsite, Server Web

\section{Pendahuluan}

Jaringan komputer tentu sangat bermanfaat bagi banyak pihak, baik itu instansi pemerintah maupun swasta, salah satu manfaat nyata dari sistem jaringan komputer adalah ketersedian data informasi yang dibutukan seseorang tanpa mengenal lagi yang namanya jarak. Dengan besarnya manfaat yang dapat diproleh dari jaringan komputer saat ini, membuat semua pihak ingin menerapkan sistem jaringan komputer pada instansi tempat mereka bekerja dengan tujuan mendapatkan kemudahan dalam menyelesaikan semua pekerjaan didalam kantor. Termasukan pada SD Negeri 15 Pangkalpinang ingin sekali menerapkan suatu Server Web Hosting dalam sistem jaringan komputer yang dimilikinya, sebuah Server Web Hosting yang dapat memberikan banyak layanan pada komputer client, terutama layanan ketersedian data informasi yang dibutukan oleh Kepala sekolah, Tata
Usaha, Guru, Siswa, Orang Tua Siswa serta masyarakat. Server Web Hosting tersebut selain bisa diakses secara lokal harus bisa juga diakses secara online dengan tujuan semua aplikasi milik sekolah yang berbasis web bisa disimpan pada satu komputer yaitu Server Web Hosting, dengan demikian semua aplikasi milik sekolah berbasis web bisa diakses warga sekolah dengan cepat dan kapan saja.

Aplikasi milik sekolah tersebut misalnya Website Sekolah, PSB Online, Ujian Online, Tugas Online, Elerning, Website Perpustakaan. Selama ini untuk menjalankan semua aplikasi berbasis website tersebut, SD Negeri 15 Pangkalpinang hanya menggunakan Web Hosting prabayar dari provider penyedia jasa Web Hosting yang ada di internet. Dalam hal tersebut semakin lama SD Negeri 15 Pangkalpinang akan semakin banyak memanfaatkan aplikasi berbasis website. Selain itu data informasi sekolah dituntut juga bisa diakses dengan cepat dan kapan saja, dengan kondisi demikian tidak menutup kemungkinan menuntut SD Negeri 15 Pangkalpinang akan menggunakan space Web Hosting semakin besar dan biaya yang ditimbulkan juga semakin besar,sehingga SD Negeri 15 Pangkalpinang menginginkan pembuatan sebuah Server Web Hosting sendiri.

\section{TinjauAn PUSTAKA}

\section{A. DNS Server}

Didik Subyantara menyatakan DNS (Domain Name System) adalah suatu sistem yang dapat menerjemahkan IP address menjadi nama suatu host. DNS digunakan untuk mempermudah mengakses sebuah komputer dalam jaringan internet atau intranet dengan hanya menuliskan nama host tersebut [12].

\section{B. Web Server}

Wahana menyatakan Web server adalah sebuah sistem yang menyediakan tempat bagi halaman web agar dapat diakses oleh browser [4]. 


\section{FTP Server}

FTP (File Transfer Protocol) merupakan protokol yang berguna untuk transfer data antar komputer maupun antar jaringan.

\section{D. $M y S Q L$}

MySQL adalah database yang menghubungkan script PHP menggunakan perintah query dan escaps character yang sama dengan PHP [5].

\section{E. File Sharing}

File sharing adalah aktifitas di mana para pengguna jaringan dapat berbagi file dengan pengguna jaringan lainnya dengan cara penyedia file terlebih dahulu mengupload file ke komputer server dan kemudian para pengguna internet yang lainnya dapat mendownload file tersebut dari komputer server.

\section{F. Mail Server}

Mail Server adalah sebuah aplikasi yang menerima e-mail dari pengguna lokal dengan domain yang sama, maupun pengirim remote dari jaringan internet.

\section{G. Zpanel}

Zpanel adalah Control Panel Open Source web hosting yang dapat berjalan di Sistem Operasi Windows, Linux, OS X, maupun Unix [13].

\section{H. Flowchart}

Flowchart adalah penggambaran secara grafik dari langkah-langkah dan urut-urutan prosedur dari suatu program. Flowchart menolong analis dan programmer untuk memecahkan masalah kedalam segmen-segmen yang lebih kecil dan menolong dalam menganalisis alternatif-alternatif lain dalam pengoperasian [2].

\section{Metode Penelitian}

Untuk menggambarkan langkah-langkah metode penelitian yang dilakukan dalam melakukan penelitian ini, penulis melakukan beberapa langkah pengerjaan yang akan diperlihatkan dalam bentuk flowchart sebagai berikut:

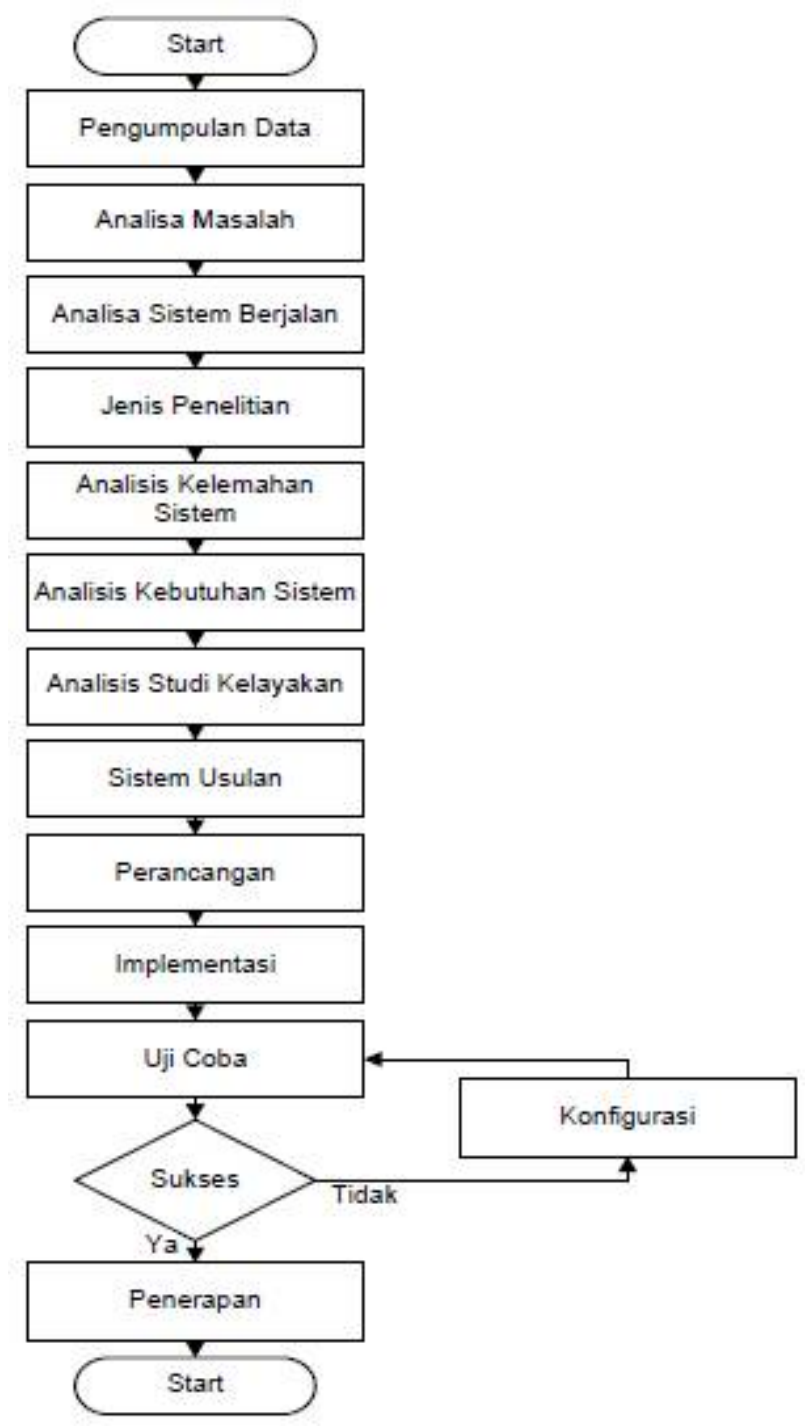

Gambar 1. Alur Metode Penelitian

\section{A. Metode Pengumpulan Data}

1) Metode Interview

Metode Interview adalah pengumpulan data dengan melakukan tanya jawab secara langsung kepada kepala sekolah, tata usaha, administrator jaringan komputer pada SD Negeri 15 Pangkalpinang.

\section{2) Metode Observasi}

Metode Observasi adalah suatu cara yang dilakukan untuk pengumpulan data dan informasi dengan melihat lansung objek penelitian pada SD Negeri 15 Pangkalpinang.

\section{3) Metode Literatur}

Metode Literatur adalah suatu cara pengumpulan data dengan cara membaca dan mempelajari litelatur yang ada hubungannya dengan masalah yang dihadapi. 


\section{4) Metode Dokumen Analisis}

Metode Dokumen Analisis adalah Pengambilan data melalui dokumen tertulis maupun elektronik dari lembaga atau institusi.

\section{B. Analisis}

Dalam hal ini, analisis bertujuan memberikan gambaran tahap-tahap yang dilakukan dalam mengidentifikasi permasalahan yang ada. Penelitian ini menggunakan teknik Identifikasi Objek Penelitian yang bertujuan untuk mengidetifikasi object penelitian yang meliputi gambaran umum perusahaan seperti sejarah berdiri perusahaan, visi-misi, struktur organisasi, tugas dan tanggung jawab.

\section{Analisis Sistem Berjalan}

Analisa sistem berjalan bertujuan untuk mengetahui permasalahan dan spesifikasi perangkat keras serta perangkat lunak yang ada pada jaringan komputer di SD Negeri 15 Pangkalpinang.

\section{1) Analisa Perangkat Keras}

Analisis Perangkat Keras berfungsi memberikan gambaran tentang perangkat keras yang saat ini digunakan pada konfigurasi sistem jaringan komputer SD Negeri 15 Pangkalpinang.

\section{2) Analisa Perangkat Lunak}

Analisis Perangkat Lunak berfungsi memberikan gambaran tentang perangkat lunak yang saat ini digunakan di SD Negeri 15 Pangkalpinang.

\section{Jenis Penelitian}

Jenis penilitian yang akan digunakan adalah jenis Penelitian Terapan. Yaitu penelitian untuk menunjang kegiatan pengembangan atau penerapan suatu sistem seperti konsep jaringan.

\section{E. Analisis Kelemahan Sistem}

Analisis kelemahan sistem bertujuan untuk memberikan gambaran tentang kekurangan yang ada pada sistem jaringan komputer di SD Negeri15 Pangkalpinang. Kelemahan tersebut yaitu belum memiliki:

- Server Website

- FTP Server

- Mail Server

- File Server

\section{F. Analisis Kebutuhan Sistem}

Analisis Kebutuhan Sistem ini memberikan gambaran tentang perangkat keras dan perangkat lunak serta topologi pemasangan server yang Jurnal TI-Atma STMIK Atma Luhur Pangkalpinang diperlukan untuk membangun Server Web Hosting pada SD Negeri 15 Pangkalpinang.
1) Kebutuhan Perangkat Keras Server

Yaitu spesifikasi perangkat keras yang dibutukan untuk membangun sebuah Server Web Hosting di SD Negeri 15 Pangkalpinang.

\section{2) Kebutuhan Perangkat Lunak Server}

Yaitu jenis-jenis perangkat lunak yang dibutuhkan untuk mendukung perancangan Server Web Hosting di SD Negeri 15 Pangkalpinang.

\section{3) Kebutuhan Jasa Layanan Register}

Yaitu jasa layanan yang dibutuhkan agar server yang sudah selesai dibuat bisa diakses lewat via internet.

\section{4) Kebutuhan Perangkat Jaringan}

Yaitu perangkat jaringan yang dibutuhkan agar Server Web Hosting yang sudah dibuat bisa di koneksikan ke dalam jaringan lokal.

\section{5) Kebutuhan Konfigurasi Topologi}

Yaitu topologi yang diusulkan untuk digunakan agar server yang sudah dibuat dapat dikoneksikan pada jaringan lokal supaya server bisa diakses oleh komputer client.

\section{G. Studi Kelayakan}

Dalam menilai suatu proyek, perlu diadakannya studi kelayakan untuk mengetahui apakah proyek tersebut layak untuk dijalankan atau tidak. Study kelayakan tersebut yaitu Analisis Kelayakan Teknik, Analisis Kelayakan Hukum, Analisis Kelayakan Operasional.

\section{H. Sistm Usulan}

Sistem usulan bertujuan memberikan gambaran tentang sistem yang diusulkan untuk memenuhi dari kebutuhan sistem yang dibutuhkan serta memperbaiki infrastruktur dari sistem jaringan sebelumnya. Agar sistem yang diusulkan dapat berjalan maka harus di dukung perangkat keras dan perangkat lunak serta topologi yang mendukung.

1) Perangkat Keras Server Usulan

Untuk melakukan perancangan Server Web Hosting di SD Negeri 15 Pangkalpinang diusulkan menggunakan perangkat keras dengan spesifikasi yang telah ditentukan agar sistem nantinya dapat bekerja dengan baik.

\section{2) Perangkat Lunak Server Usulan}

Untuk melakukan perancangan Server Web Hosting di SD Negeri 15 Pangkalpinang diusulkan menggunakan perangkat lunak yang mendukung perancangan server web hosting agar sistem nantinya dapat bekerja dengan baik. 


\section{3) Jasa Layanan Usulan Register}

Agar server yang sudah selesai dibuat bisa diakses lewat via internet maka diusulkan menggunakan jasa layanan register.

\section{4) Perangkat Jaringan Usulan}

Supaya Server Web Hosting yang sudah dibuat bisa di koneksikan ke dalam jaringan lokal maka diusulkan menggunakan perangkat jaringan yang mendukung.

\section{Perancangan}

Dalam hal ini, perancangan bertujuan memberikan gambaran yang dilakukan dalam pembuatan Server Web Hosting menggunakan Linux Ubuntu Server 12.04 guna memberikan solusi dari permasalahan yang ditemukan pada saat analisis sistem berjalan.

\section{1) Perancangan Input}

Perancangan input merupakan suatu cara untuk menggambarkan perangkat lunak yang digunakan dalam proses pembuatan Server Web Hosting pada SD Negeri 15 Pangkalpinang. Dari hasil instalasi dan konfigurasi perangkat lunak dapat dilakukan penginputan berikut ini:

- Nama Domain dan Subdomain

- Acount folder FTP download

- Pembuatan Database

- Acount Email guru

- Pembuatan folder File Sharing

\section{2) Perancangan Ouput}

Dari perancangan Server Web Hosting yang diusulkan akan mengasilkan output media penyimpan website sekolah dan aplikasi berbasis website milik sekolah yang dapat diakses melalui alamat tertentu seperti berikut:

- Domain

- Subdomain

- FTP (File Transfer Protocol)

- File Sharing

- Email Guru

\section{J. Implementasi}

Tujuan implementasi adalah untuk menerapkan perancangan yang telah dilakukan terhadap sistem sehingga user dapat memberi masukan untuk perbaikan sistem yang telah dibangun.

1) Instalasi Perangkat Keras

Pada tahap instalasi perangkat keras server ini, akan membahas proses secara teknis konfigurasi pemasangan komputer server kedalam jaringan lokal.

\section{2) Instalasi Perangkat Lunak}

Pada tahap instalasi perangkat lunak ini, akan membahas proses secara teknis installasi dan kofigurasi perangkat lunak untuk membuat komputer Server Web Hosting.

\section{K. Pengujian Server}

Setelah proses installasi dan konfigurasi server selesai, Pengujian terhadap Access Server akan dilengkapi dengan pengujian menggunakan metode black box.

\section{Konfigurasi}

Jika pada saat pengujian server mengalami kegagalan proses maka dilakukan perbaikan konfigurasi ulang pada konten yang mengalami proses error sampai konten tersebut benar-benar berjalan dengan baik.

\section{Penerapan}

Setelah semua proses implementasi dan pengujian berhasil dilakukan dengan baik dan kondisi sistem server sudah fix untuk digunakan dan sudah dinyatakan tidak konten yang mengalami eror maka dilakukan penerapan sistem server pada jaringan SD Negeri 15 Pangkalpinang.

\section{HASIl DAN PEMBAHASAN}

\section{A. Instalasi Perangkat Keras}

Berikut gambar diagram hasil pemasangan server pada jaringan.



Gambar 2. Hasil Instalasi Perangkat Keras

\section{B. Instalasi Perangkat Lunak}

Server Web Hosting dibuat menggunakan perangkat lunak sesuai dengan yang diusulkan pada proses perancangan sebelumnya.

1) Instalasi Sistem Operasi Ubuntu

Server Web Hosting menggunakan Linux Ubuntu Server 12.04 Lts sebagai Sistem Operasi, Berikut proses pelaksanaan instalasi Sistem Operasi Server. 


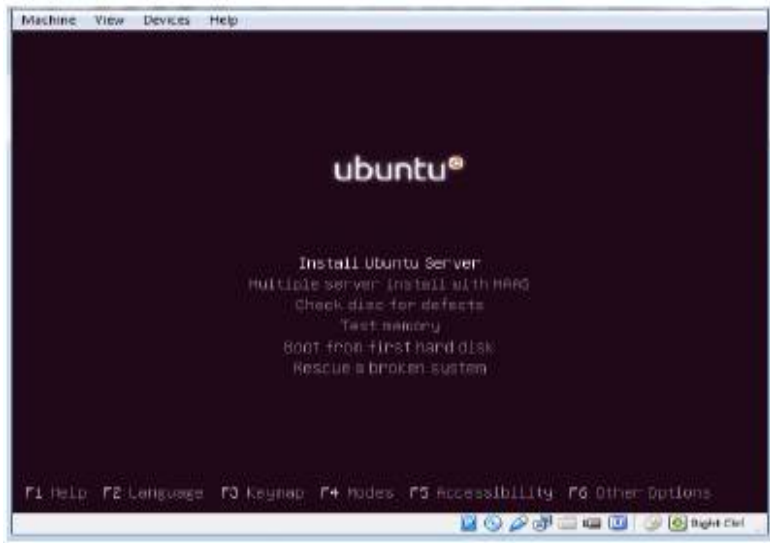

Gambar 3. Instalasi Sistem Operasi Ubuntu

\section{2) Instalasi Kernel Sistem Operasi Ubuntu}

Pada tahap ini dilakukan penginstalan semua paket kernel yang mendukung sistem operasi ubuntu dalam pembuatan Server Web Hosting.

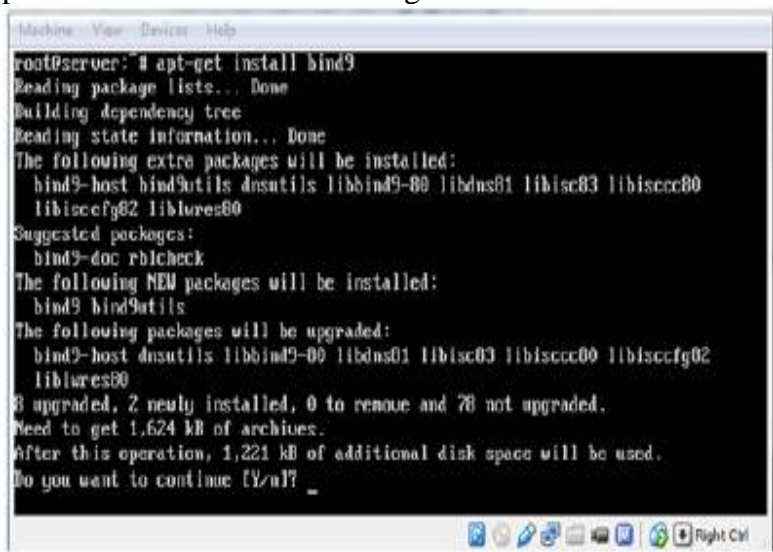

Gambar 4. Instalasi Kernel Sistem Operasi Ubuntu

\section{3) Instalasi Aplikasi Server}

Pada tahap ini dilakukan penginstalan semua paket Aplikasi yang mendukung sistem operasi ubuntu dalam pembuatan Server Web Hosting.



Gambar 5. Instalasi Aplikasi Server

\section{Konfigurasi Server}

Pada tahap ini adalah tahap Konfigurasi Sever yang dilakukan dengan tujuan mengkonfigurasi paket kernel dan software aplikasi pendukung server yang sudah di instalasi agar dapat berkerja dan berjalan dengan baik dalam memberikan layanan-layanan sesuai dengan peruntukannya.



Gambar 6. Konfigurasi Pembuatan Nama Domain

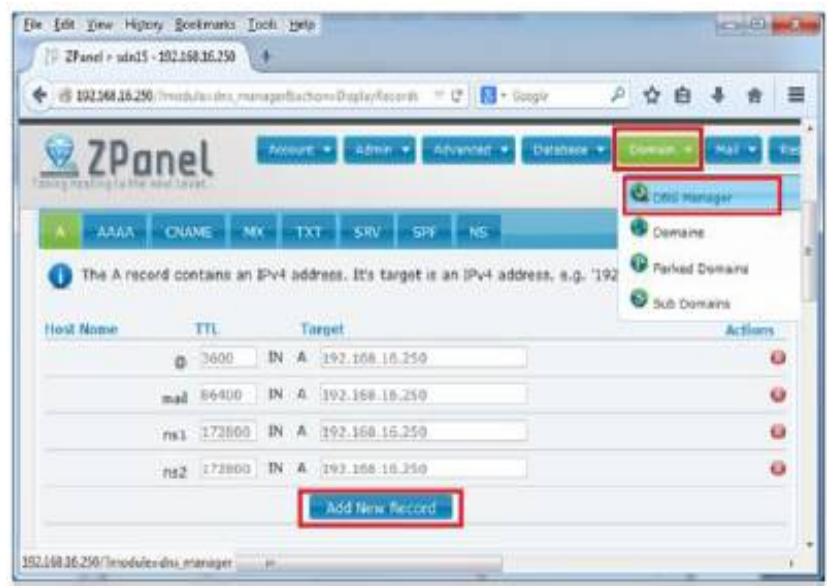

Gambar 7. Konfigurasi Pembuatan Record Nama Domain

\section{Pengujian Server}

Setelah proses instalasi dan konfigurasi sistem server selesai, maka perlu dilakukan test pengujian server. Hal ini dimaksudkan untuk melihat apakah instalasi dan konfigurasi system server mulai dari memasang kabel sampai dengan konfigurasi sistem secara software telah dilakukan dengan benar.

1) Pengujian Dengan Metode Black Box

Pada tahap ini dilakukan pengujian system server dengan tabel Black Box dengan tujuan untuk mengetahui hasil instalasi dan konfigurasi yang telah dilakukan. Jika pada pengujian ditemukan error pada server maka segera diperbaiki. Berikut ini tabel pengujian black box Server Web Hosting yang dibuat pada SD Negeri 15 Pangkalpinang. 
Tabel 1. Metode Black Box

\begin{tabular}{|c|c|c|c|c|c|c|}
\hline $\mathrm{Not}$ & $M u=i t y$ & Aat 15 & Arasle Prayple & 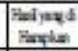 & $\begin{array}{c}H=1 \\
\mathrm{GF}\end{array}$ & Kat \\
\hline & 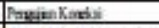 & & & & & \\
\hline & 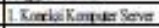 & 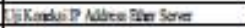 & 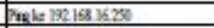 & $\operatorname{tin}$ & 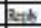 & $\operatorname{sos}$ \\
\hline & & Kondui Seng ke Routs & Pagle 132158.62 .24 & $\sin$ & $3+3$ & $50=$ \\
\hline & & 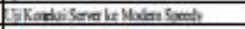 & 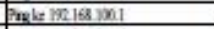 & $\operatorname{tin}$ & 390 & $50 \mathrm{~s}$ \\
\hline & & Fandi:5erate DN5 & 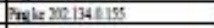 & $\sin$ & 3 tab & \\
\hline & & 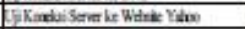 & Pryla vómient & $\sin$ & 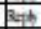 & $50=$ \\
\hline & & 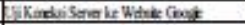 & Frabs acitial & $\operatorname{tin}$ & sath & Sare \\
\hline & & 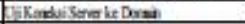 & 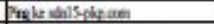 & $\operatorname{tin}$ & kath & 50 \\
\hline & & Karbil Serra kt indmi & 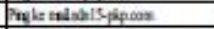 & $\sin$ & 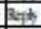 & 500 \\
\hline & & 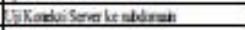 & Fris pesulsyagen & $\operatorname{tin} x$ & 3 ath & 60 \\
\hline & & & 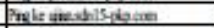 & $\tan$ & 3 की & $\operatorname{Sos}$ \\
\hline & & & 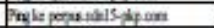 & $\sin$ & $3+\infty$ & $5 o=$ \\
\hline & & & 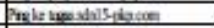 & Fing & sith & 5 Sas \\
\hline & & & 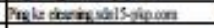 & $\operatorname{tin}$ & $3+3$ & 5 \\
\hline & & & & & & \\
\hline & 2 Sinibeloquer Sm & 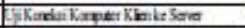 & 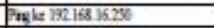 & $\tan$ & Eth & $50 x$ \\
\hline & & 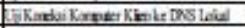 & Fals 19216825200 & $\operatorname{tin}$ & 30 & $\sin 5$ \\
\hline & & 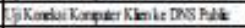 & 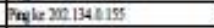 & $\sin$ & $3+6$ & $50 \mathrm{~s}$ \\
\hline & & 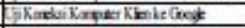 & 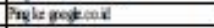 & $\sin$ & 3 as & 560 \\
\hline & & 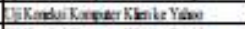 & Fristsonen & $\sin$ & $3+3$ & $\operatorname{Sos}$ \\
\hline & & 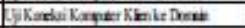 & 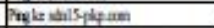 & $\sin$ & 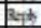 & 50 \\
\hline & & 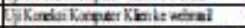 & 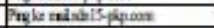 & $\tan$ & Eक⿱ & $50 x$ \\
\hline & & 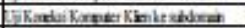 & Freks phadus spiaen & $\operatorname{tin}$ & $3=$ & $\operatorname{sen}$ \\
\hline & & & 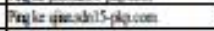 & $\sin$ & 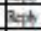 & $50=$ \\
\hline & & & 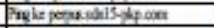 & $\sin$ & 3 & 500 \\
\hline & & & 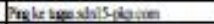 & $\operatorname{tin}$ & 3to & 50 \\
\hline & & & 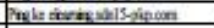 & $\sin$ & $3+3$ & sos \\
\hline & & & & & & \\
\hline$B$ & Hichationes & 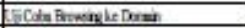 & Prominkestilspipem & $\sin$ & $2 x_{t}$ & Sose \\
\hline & & 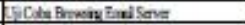 & 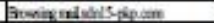 & $\sin$ & $8 x_{t}$ & 50 \\
\hline & & 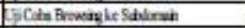 & 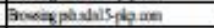 & $\operatorname{san}$ & $a_{t}$ & $50=$ \\
\hline & & & 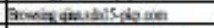 & $\tan$ & $a t$ & $\operatorname{son}$ \\
\hline & & & 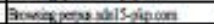 & $\sin$ & $x_{n t}$ & sos \\
\hline & & & 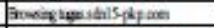 & $\tan$ & ott & $50 \mathrm{se}$ \\
\hline & & & 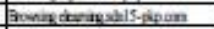 & $\operatorname{tin}$ & $2 x_{t}$ & $\sin$ \\
\hline & &  &  & $\sin$ & $9 x_{t}$ & 50 \\
\hline & &  &  & tant & $a_{t}$ & 500 \\
\hline & & & 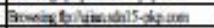 & $\operatorname{tin}$ & $2 x_{t}$ & $\operatorname{sos}$ \\
\hline & & &  & $\sin$ & $g_{t i t}$ & 6 \\
\hline & & & 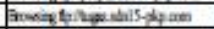 & $\tan$ & $8 t$ & $50=$ \\
\hline & & & 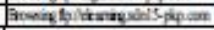 & $\sin$ & atst & Sos \\
\hline C & Fichen Fising & Ficond Noes Fit Shitg & Brishlispinoon & lises & $\alpha=$ & $\operatorname{sen}$ \\
\hline & & & Re inatis pquoriphix & Hose & as & ene \\
\hline & & & 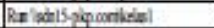 & thes & $\alpha z$ & enes. \\
\hline & & &  & 1bses & $\alpha=$ & iena \\
\hline & & &  & 15ses & $\alpha s$ & 20 \\
\hline & & & 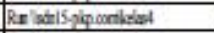 & Nhes: & $\alpha=$ & iens \\
\hline & & & 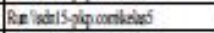 & Noso & $\alpha s$ & seses \\
\hline & & & 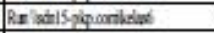 & 1608 & $d e$ & 20 \\
\hline & & & & & & \\
\hline 0 & FCoharit Seve & 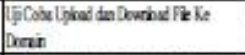 & Core FTP sath 15 plpom & thes & $\alpha=$ & ence \\
\hline & & 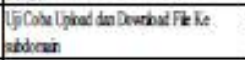 & Core PTP pesteis solpon & 1608 & $\alpha=$ & Sene \\
\hline & & & 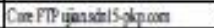 & thes & $\alpha z$ & enes \\
\hline & & & CorefTPrens unisplocan & ibso & $\alpha=$ & 2 \\
\hline & & & 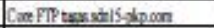 & Hess & $d=$ & 20 \\
\hline & & & 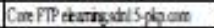 & these & $\alpha c$ & enses \\
\hline
\end{tabular}

\section{2) Pengujian dengan Command Prompt}

Untuk mengetahui apakah domain Sesuai dan subdomain yang telah dikonfigurasi telah berjalan dengan baik atau belum maka dilakukan pengujian status koneksi. Untuk melihat status koneksi domain dan subdomain dilakukan pengujian dengan ping ke domain dan subdomain yang telah dibuat.

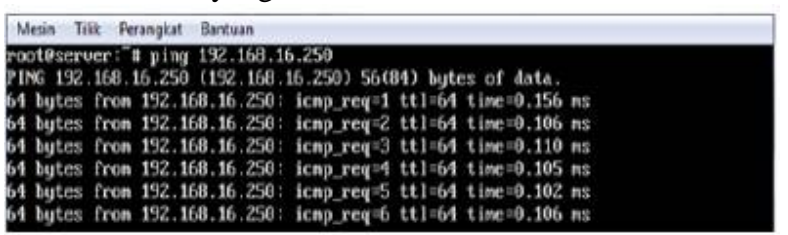

Gambar 8. Pengujian dengan Ping ke IP Address Server

\section{3) Pengujian dengan Web Browser}

Untuk melakukan pengujian operator menggunakan web browser mozilla dari komputer client untuk mengakses web server yang terinstall pada server web hosting.

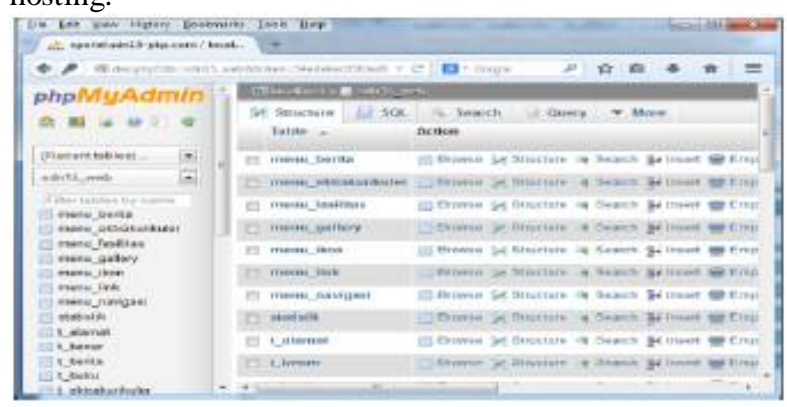

Gambar 9. Tampilan Database phpmyadmin

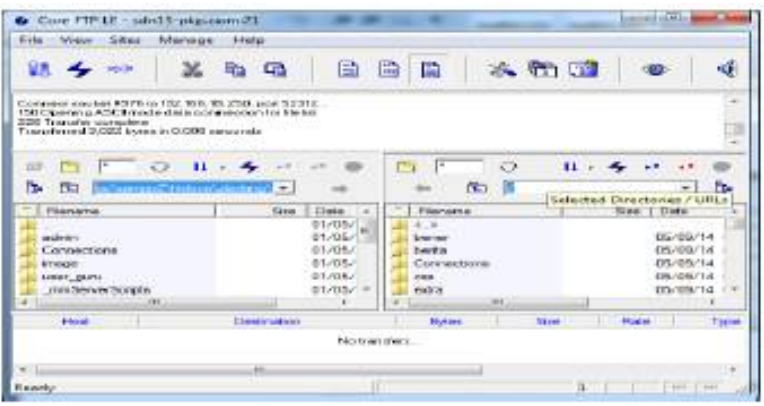

Gambar 10. Proses Upload dengan FTP

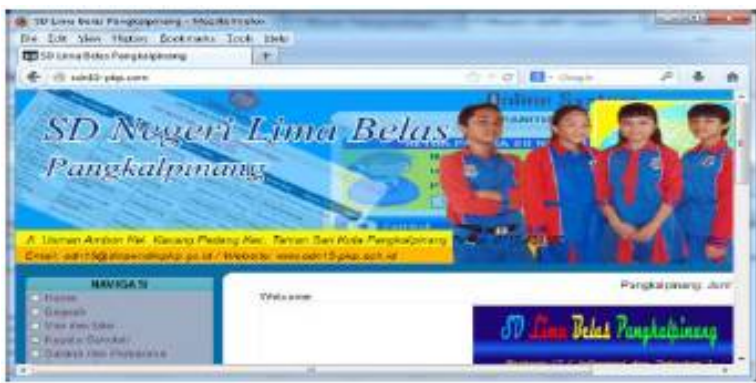

Gambar 11. Akses Website Sekolah dengan Nama Domain Lokal

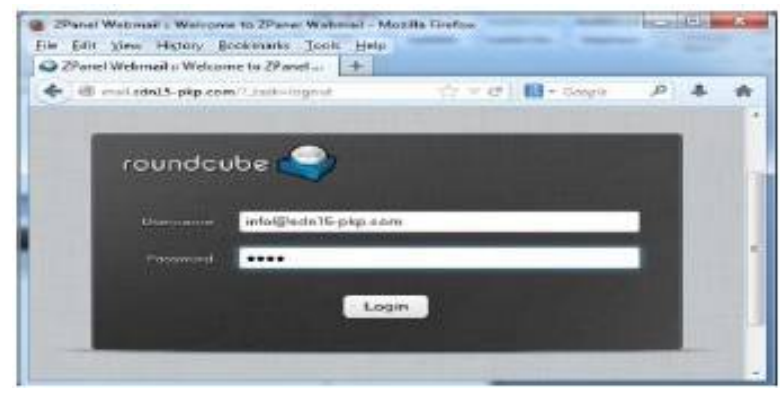

Gambar 12. Akses Web Mail Server dengan Nama Subdomain 


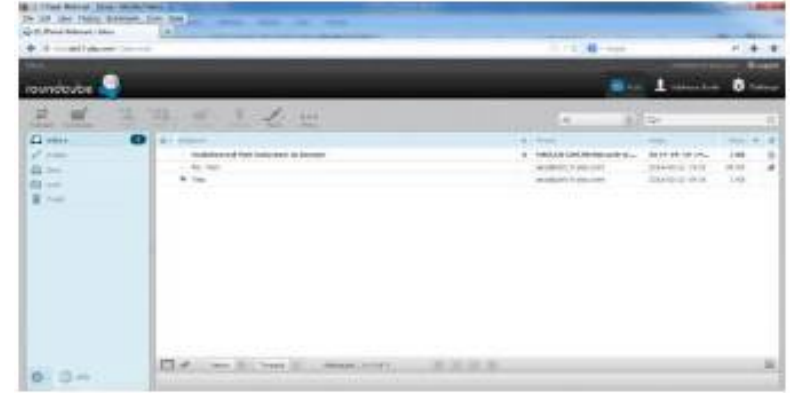

Gambar 13. Proses Akses Halaman Email User Guru

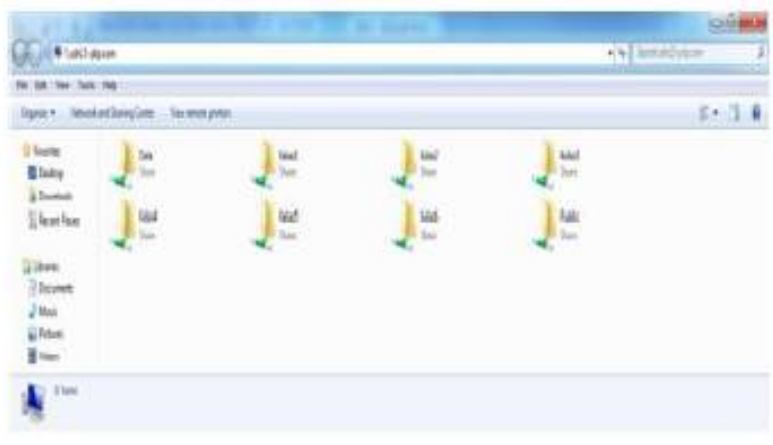

Gambar 14. Proses Akses File Sharing

\section{Penutup}

\section{A. Kesimpulan}

Dari pembahasan yang sudah disampaikan maka penulis mencoba membuat beberapa kesimpulan seperti :

- Terciptanya satu unit Komputer Server Web Hosting yang dapat diterapkan pada SD Negeri 15 Pangkalpinang baik secara intranet atau dapat juga dikoneksikan ke internet.

- Dengan Server Web Hosting ini memberikan kemudahan kepada pihak sekolah khususnya administrator sistem dalam pengelolan penyimpanan aplikasi berbasis website milik sekolah.

- Tersedianya media penyimpanan aplikasi berbasis website yang tidak membutuhkan biaya tagihan perbulan.

- Dengan adanya Server Web Hosting terwujudnya pengembangan infrastruktur sistem jaringan komputer yang baik dan dapat nantinya digunakan dalam jangka panjang di SD Negeri 15 Pangkalpinang, serta menerapkan system jaringan berkelanjutan sebagai pengembangan sistem informasi pada SD Negeri 15 Pangkalpinang.

\section{B. Saran}

Adapun beberapa hal yang dapat disampaikan sebagai bahan pertimbangan untuk pengembangan kedepannya antara lain :
- Untuk pengembangan server diharapkan bisa dikembangkan untuk menggunakan hardware yang memiliki spesifikasi cukup tinggi, agar dapat menyediakan layanan yang cukup tinggi juga, serta menyediakan media penyimpanan yang lebih banyak lagi.

- Dalam penerapan sistem Server Web Hosting ini, komputer server harus dapat aktif dalam waktu 24 Jam.

- Untuk kedepannya sebaiknya Server Web Hosting tidak hanya digunakan untuk SD Negeri 15 Pangkalpinang saja tetapi dapat juga diperuntukkan sebagai media bisnis Server Web Hosting agar dapat memberikan pemasukan modal ke pihak SD Negeri 15 Pangkalpinang.

\section{DAFTAR PUSTAKA}

[1] D. Adi, P. Eka, (2012), Mengenal Aplikasi Microsoft Visio 2010, Universitas Brawijaya, diakses pada 3 Juni 2014, <http://blog.ub.ac.id/>.

[2] M. Faisal, (2011), flowchart diagram alur, Mandar, diakses pada 2 Juni 2014, <http://www.mandar.web.id/>.

[3] M. P. Islamiah, (2012), Microsoft Project 2010, Indonesia Student Portal, diakses pada 3 Juni 2014, $<$ http://students.netindonesia.net/>.

[4] Wahana, (2008), Administrasi Jaringan Menggunakan Linux Ubuntu 7, Andi Offset, Yogyakarta

[5] R. Kurniawan, (2008), Membangun Situs dengan PHP Untuk Orang Awam, Maxikom, Palembang.

[6] Kustanto, (2008), Membangun Server Internet dengan Mikrotik, Gava Media, Yogyakarta

[7] V. Listanto, (2011), Teknik Jaringan Komputer, Prestasi Pustaka Publisher, Jakarta.

[8] Madcoms, (2003), Dasar Teknisi Instalasi Jaringan Komputer, Andi, Yogyakarta

[9] Mulyanta, S.Si, E.S., (2005), Pengenalan Protokol Jaringan Wireless Komputer, Andi, Yogyakarta

[10] Munawar, (2005), Pemodelan Visual dengan UML, Graha Ilmu, Yogyakarta.

[11] O. W. Purbo, (2006), Buku Pengangan Internet Wireless dan HostSoot, Elex Media Komputindo, Jakarta.

[12] D. Subyantara, (2004), Instalasi dan Konfigurasi Jaringan Microsoft Windows, Elex Media Komputindo, Jakarta

[13] D. Suprianto, (2008), Buku Pintar Pemrograman PHP, Oase Media, Bandung.

[14] M. Syafrizal, (2005), Pengantar Jaringan Komputer, Andi, Yogyakarta.

[15] A. Zaki, (2008), PHP dan MySQL, Elex Media Komputindo, Semarang. 